\title{
Adventures in 3D Printing Using TINKERCAD + 3D Printer
}

\author{
Tom Hsieh ${ }^{1}$
}

${ }^{1}$ Affiliation not available

April 23, 2021

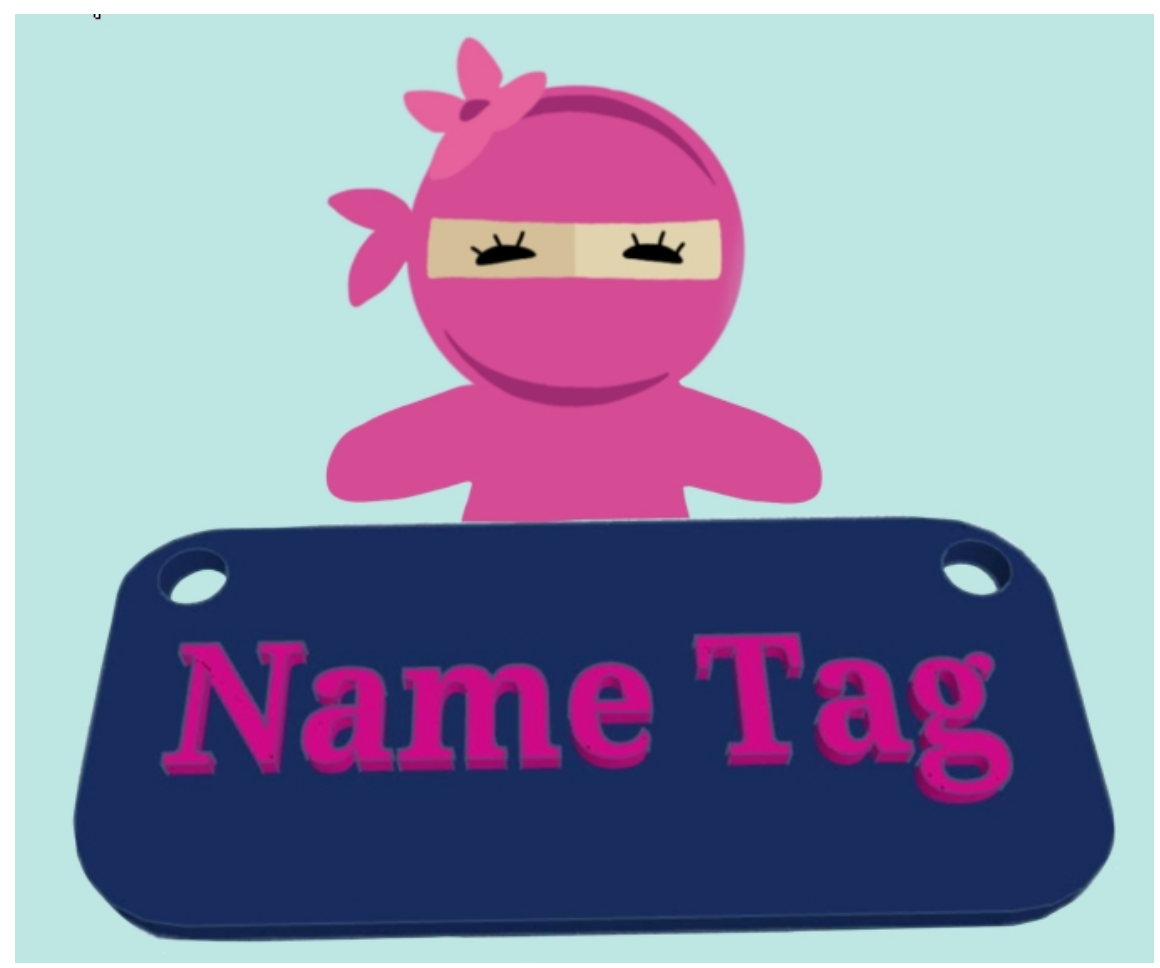

Figure 1: Name Tag using TINKERCAD

\section{Overview:}

The process of 3D printing is essentially a manufacturing technology to create objects in three dimensions using various materials heated to a temperature that allows them to be formed into different shapes. 3D printing has gained much popularity in the past few decades due to availability of cost-effective 3D printers as well as books/knowledge source on how to use 3D printers. It is a convenient way to create prototypes or customized items for inventors and novice who likes to create their own designs. Prior to 3D printing, 3D model (typically in STL file format) needs to be created through software like TINKERCAD to create the design shapes ideal for printing. The lesson here is focus on 3D modelling using TINKERCAD rather than detail 3D printing which is more hardware focus. 


\section{Lesson Objectives}

- Students will explore a foundation in 3D modeling by designing simple structures. Students will learn tips, techniques and associated best practices for exciting explorations in 3D modelling and printing.

- Students will create a name tag using TINKERCAD with detail step-by-step instruction

- Students will work independently using TINKERCAD after completing the initial name tag design to create another design that is useful and can be apply to daily use (pencil box, soap holder, bookmark, bookend, etc..)

- Students are encourage to further their learning and creating design and publish it on open source such as Thingiverse.

\section{Vocabulary}

- 3D model

- Computer-aided design (CAD)

- Additive Manufacturing

- Extrusion

- Filament

- SnapGrid

- STL File

- Workplane

- Solid / Hole

\section{Suggested time:}

\section{0 minutes (best to break into 3 parts)}

\section{Suggested age level: $\quad 8+$}

\section{Required and optional materials:}

- TINKERCAD (FREE, need to create an account)

- Markers / Pencils / Paper

- Scissors / Tape or glue

- 3D Printer (Optional, only if you want to print out your designs). A list of popular 3D printers with various price point and functionality can be found in this link. If you are looking for specific 3D printer with enclosure as well as dual extruder (allow you to print 2 different color), we will recommend to use the FlashForge Creator Pro.

- 3D Printer Filament (Optional, only if you want to print out your designs). You can find many 3D printer filament materials on the market, the dominate filament type is ABS or PLA. We recommend to use PLA as it is the least toxic filament. For more guidance on what filament to choose and safety tips, please read through the safety tips article here.

Reflection: *Specific printer and filament are recommendations. Feel free to use another make or model. Also, be aware that 3D printers are slow; the quality of the design also depend on the resolution of the printing. Prior to create your design, you should consider the difficulty of the print (shapes) and the duration of the print (size). 


\section{Optional resources}

1. Amazon.com: Tinkercad For Dummies (9781119464419): Bryant, Shaun C.: Books

2. 3D Printing and Maker Lab for Kids: Create Amazing Projects with CAD Design and STEAM Ideas (Lab for Kids, 22): Sequeira, Eldrid: 9781631597992: Amazon.com: Books

3. 3D Printing \& Sudoku Lovers Puzzle Activity Gift Book: Depot, Mega Media: 9798632850827: Amazon.com: Books

4. 3D Printing Failures: 2020 Edition: How to Diagnose and Repair ALL Desktop 3D Printing Issues: Aranda, Sean, Feeney, David: 9781710054590: Amazon.com: Books

\section{Lesson Plan (Part 1: 60 min)}

Go to TINKERCAD and completed the STARTER lessons (total of 4)

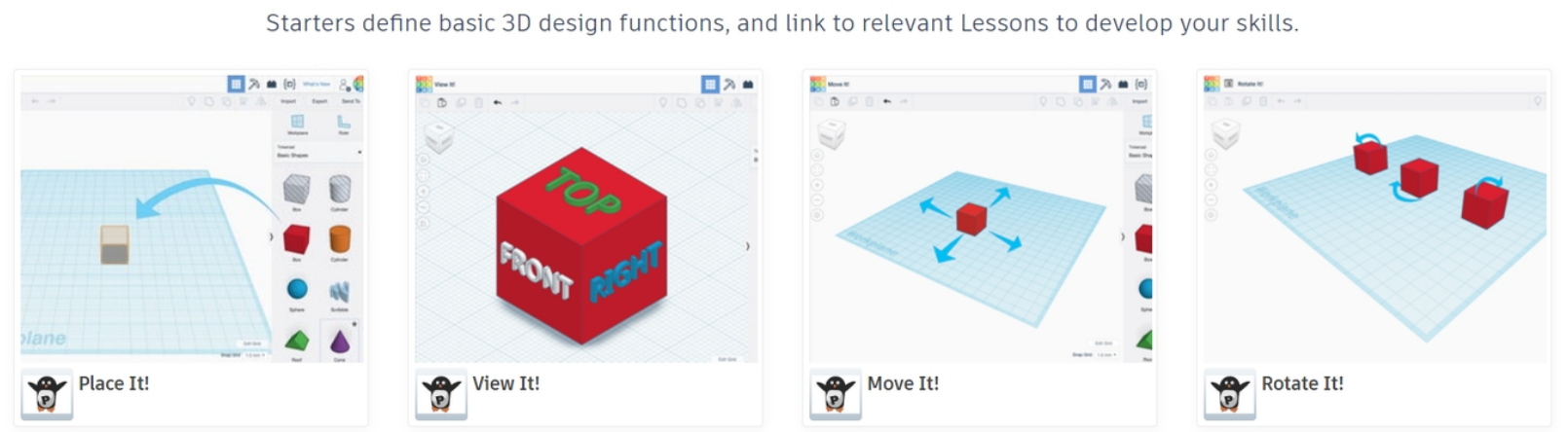

Figure 2: Basic operations on shapes

Below is an extremely useful TINKERCAD shortcut keys to use.

\section{Hosted file}

tinkercad-keyboard-shortcuts_revised-8-31-182.pdf available at https://authorea.com/users/ 409539/articles/519171-adventures-in-3d-printing-using-tinkercad-3d-printer

\section{Lesson Plan (Part 2: 60 min)}

Follow the instruction below to complete your name tag, make sure to apply the short cut techniques shown above to speed-up the creation of your design.

\section{Hosted file}

CodeNinja_Nametag.pdf available at https://authorea.com/users/409539/articles/519171adventures-in-3d-printing-using-tinkercad-3d-printer

\section{Reflection:}

Do you think there is a different approach to design the name tag? What are the design trade-off in terms of complexity and \# of steps and shaped used? Does it compromise the design when it comes to actual printing stage? 


\section{Lesson Plan (Part 3: 120min)}

Now, you are ready to create your own design that you can actual print and use it. Make sure to apply the design so it is actually printable (with reasonable time to print), if you are printing with round or shapes with many curve, make sure you provide support during printing.

\section{Reflection:}

- In the printed object, is it lighter or heavier than you expected? Why do you think it is so?

- Did you get a chance to see the inside of the object as it was printing? What did it look like?

- What do you notice about the curved shape of the design (its texture, its roundness)?

- Is there a limitation to the size of a hole in an object? If so, why?

- List two different architectural styles that are incorporated in your design

- How could you modify the design so it can be print faster? or more sturdy? 